IZA DP No. 9376

Secondary Childcare in the ATUS:

What Does It Measure?

Jay Stewart

Mary Dorinda Allard

September 2015

Forschungsinstitut zur Zukunft der Arbeit Institute for the Study of Labor 


\title{
Secondary Childcare in the ATUS: What Does It Measure?
}

\author{
Jay Stewart \\ U.S. Bureau of Labor Statistics \\ and IZA \\ Mary Dorinda Allard \\ U.S. Bureau of Labor Statistics
}

\section{Discussion Paper No. 9376 \\ September 2015}

\author{
IZA \\ P.O. Box 7240 \\ 53072 Bonn \\ Germany \\ Phone: +49-228-3894-0 \\ Fax: +49-228-3894-180 \\ E-mail: iza@iza.org
}

\begin{abstract}
Any opinions expressed here are those of the author(s) and not those of IZA. Research published in this series may include views on policy, but the institute itself takes no institutional policy positions. The IZA research network is committed to the IZA Guiding Principles of Research Integrity.

The Institute for the Study of Labor (IZA) in Bonn is a local and virtual international research center and a place of communication between science, politics and business. IZA is an independent nonprofit organization supported by Deutsche Post Foundation. The center is associated with the University of Bonn and offers a stimulating research environment through its international network, workshops and conferences, data service, project support, research visits and doctoral program. IZA engages in (i) original and internationally competitive research in all fields of labor economics, (ii) development of policy concepts, and (iii) dissemination of research results and concepts to the interested public.
\end{abstract}

IZA Discussion Papers often represent preliminary work and are circulated to encourage discussion. Citation of such a paper should account for its provisional character. A revised version may be available directly from the author. 
IZA Discussion Paper No. 9376

September 2015

\section{ABSTRACT}

\section{Secondary Childcare in the ATUS: What Does It Measure?*}

Unlike most of the earlier U.S. time-use surveys, the American Time Use Survey (ATUS) does not collect information on secondary activities. It does, however, include a set of questions asking respondents to identify times when a child under 13 was "in your care." The goal of these questions is to measure the amount of time that respondents spend looking after children while doing something else. The respondent need not be actively engaged with the child, but must have a general idea of what the child is doing and be available to help if necessary. Although questions similar to these have been asked for a number of years in the Statistics Canada time use survey, very little research has been conducted to assess the quality of these data. This paper investigates whether the secondary childcare questions in the ATUS are measuring the stated concept. We look for inconsistencies in the data and examine certain, potentially problematic, reporting patterns. We also construct alternative estimates that exclude time spent in secondary childcare that is inconsistent with other data collected during the interview and find that the ATUS measure overestimates secondary childcare by at most 5 percent or about 16 minutes per day.

JEL Classification: $\quad \mathrm{C} 83, \mathrm{~J} 13, \mathrm{~J} 22$

Keywords: $\quad$ survey methods, childcare, time use

Corresponding author:

Jay Stewart

U.S. Bureau of Labor Statistics

2 Massachusetts Ave., NE

Washington, DC 20212

USA

E-mail: Stewart.Jay@bls.gov

* Any views expressed here are ours and do not necessarily reflect those of the Bureau of Labor Statistics. We thank Suzanne Bianchi and Dan Hamermesh for helpful comments. 


\section{Introduction}

Time-use surveys are a primary source of data for studying parental investment in children — an important topic that has been researched extensively. Numerous studies have examined how much time parents spend in childcare activities by parental employment and marital status, as well as long-term trends in parental time spent in childcare. In addition to these questions, time-use surveys are useful for measuring the aggregate amount of time devoted to childcare activities. Much of this time, especially time spent looking after children, satisfies the third-person criteria for household production and should be included in nonmarket satellite accounts to the National Income and Product Accounts. ${ }^{1}$ Thus, it is important to have accurate measures of the time spent in childcare.

Researchers have most often used three measures of childcare to examine parental investment in their children: childcare done as a primary activity (which we refer to as primary childcare), time spent with children, and, to a lesser extent, childcare done while doing something else (secondary childcare). In this paper, we examine all three of these measures using data from the American Time Use Survey (ATUS), although our focus is the measure of secondary childcare.

The distinguishing characteristic of primary childcare is that it is respondents' main activity when they are asked what they were doing. Primary childcare includes activities such as reading and playing with children, as well as activities such as feeding, bathing, and dressing children. Time with children measures time that parents are physically with their children, and is more a measure of children's access to their parents.

\footnotetext{
${ }^{1}$ See Landefeld, Fraumeni, and Voitech (2009) for a discussion of prototype satellite accounts using ATUS.
} 
The ATUS measure of secondary childcare is a clear departure from earlier US time-use surveys, but it is similar to that of the Statistics Canada General Social Survey (GSS). In the earlier US surveys, secondary childcare was collected by asking respondents "What else were you doing?” for each of their reported activities. This question is clearly aimed at capturing all secondary activities and is not restricted to childcare. ${ }^{2}$ The ATUS has never asked the "What else were you doing?” question, but for the first several years of the survey, interviewers did record secondary activities if they were volunteered. However, secondary activities were rarely reported, and this information was not used to estimate the amount of time spent in secondary childcare. $^{3}$ Rather, the ATUS specifically asks respondents to identify times or activities during which at least one child under 13 was "in your care." Given these differences in approach, it is not surprising that estimates of secondary childcare time are considerably higher in the ATUS (and in the Statistics Canada GSS) than in earlier US time-use surveys. ${ }^{4}$

The ATUS questionnaire design team defined the ATUS secondary childcare concept and used that concept to guide the question development process. The main criterion for this definition is that the respondent must be able to provide physical assistance to the child if he or she is injured. This implies that the respondent is in the general vicinity of the child and has a general idea what the child is doing. Because respondents may be confused by, or may not be willing to listen to, long questions, the challenge faced by the ATUS team was to develop a simple question wording that conveyed the ATUS concept. A number of alternatives were cognitively tested, and the results showed that the phrase "in your care" best conveyed the

\footnotetext{
${ }^{2}$ Common secondary activities include listening to the radio, watching TV, eating, or communicating, but in principle they could be anything that could be done as a primary activity (except travel or sleep). Respondents can report that they were looking after children, but they rarely do so.

${ }^{3}$ See Drago and Stewart (2010) for an analysis of secondary activities reported in the ATUS. Volunteered secondary activities were no longer recorded by ATUS interviewers starting in 2011.

${ }^{4}$ See Allard, Bianchi, Stewart, and White (2007) for an analysis of the comparability of the ATUS measure to those from earlier time-use surveys.
} 
concept. ${ }^{5}$ Given that the "in your care" concept requires the respondent to be in the general vicinity of the child, it is more restrictive than simply "being responsible" for a child, which is a more global concept that may include times when the child is at a friend's house or at school. The ATUS concept of secondary childcare would seem to be similar to "time with children," but it differs in two important ways.

The main difference is that it is not necessary for the respondent to be "with" the child to be providing secondary childcare. In the ATUS, someone is considered to be "with" the respondent if he or she is in the same room when the respondent is at home or if he or she accompanies the respondent away from home. When the respondent is at home, the ATUS secondary childcare concept allows for situations where the child is in another part of the house or playing in the yard. But when traveling or in certain locations away from home, we would expect the respondent to be "with” a household child under 13 when providing secondary childcare. The concept also allows for the possibility that the respondent is with a child under 13, but is not looking after that child. This might be the case if both parents are present, but only one is "in charge."

Combining this measure with "time with children” provides a better measure of access to parents than relying only on reports of time with children because it includes times when parents are accessible but not in the same room. It also addresses the concern of some researchers that little attention has been paid to passive care activities. ${ }^{6}$

Our study begins by documenting the amount of time spent in these three measures of childcare and summarizing the relationship between secondary childcare and time spent with children both at the aggregate and the episode level. Next, we look for inconsistencies in the

${ }^{5}$ Other phrases that were considered are: "keeping tabs on," "looking after” (this is the Statistics Canada wording), and "responsible for." See Schwarz (2002).

${ }^{6}$ See Folbre, Yoon, Finnoff, and Fuligni (2005). 
data and examine two potentially problematic reporting patterns. Finally, we construct

alternative estimates that exclude time spent in secondary childcare that is inconsistent with other information from the interview.

We find that the secondary childcare measure in the ATUS appears to be accurately capturing passive childcare. And our alternative estimates indicate that the ATUS measure overestimates the time spent in secondary childcare by at most 5 percent or about 16 minutes per day. More generally, our results suggest that the "in your care" question elicits valid responses, thus opening the door to collecting other types of information using the same format. ${ }^{7}$

\section{Data}

The dataset for our study is a pooled sample from the 2003 and 2004 ATUS. The ATUS asks respondents to sequentially describe what they did during a 24-hour period (the “diary day”) beginning at 4:00AM the previous day through 4:00AM of the interview day. Each time period for which an activity is reported is an “episode.” For each episode, respondents are asked to report what they were doing (their primary activity), how long they were doing it, who was with them, and where they were. When the respondent reports doing more than one activity, the primary activity is the one that the respondent considers to be his or her main activity, although ATUS follows the convention in time-diary studies that traveling-even when done in conjunction with another activity, such as feeding a child-is always considered the primary activity.

\footnotetext{
${ }^{7}$ For example, the Day Reconstruction Method, which is described in Kahneman, Krueger, Schkade, Schwarz, and Stone (2004), is very similar to the ATUS approach.
} 
The ATUS collects information on secondary childcare using questions modeled after those in Statistics Canada's GSS. After the time diary has been completed, the ATUS asks respondents to identify times and activities during which a child under 13 was "in your care.”

The cognitive pretesting of the secondary childcare questions revealed some inconsistencies in how respondents answered the secondary childcare questions. In particular, some respondents included times when they or their children were asleep while others did not. ${ }^{9}$ To ensure uniformity across respondents, official Bureau of Labor Statistics (BLS) estimates of secondary childcare exclude times when the respondent or all household children under 13 were asleep. To determine when the household children were asleep, the respondent is asked to report when the first child under 13 woke up and when the last child under 13 went to sleep. ${ }^{10}$

We restricted our sample to respondents age 18 and older who had at least one own child under 13 living in the household, no non-own children living in the household, and no own children living outside the household. ${ }^{11}$ We imposed the latter restriction because the secondary childcare questions in the 2003 data do not distinguish between looking after own household, non-own household, and own non-household children. We further restricted the sample to respondents living in single-adult or married-couple households, which excludes respondents living with an unmarried partner, grandparents, adult siblings, or other unrelated adults; we did this because we felt that the childcare arrangements in these types of households may make it more difficult to determine how and for whom respondents are providing secondary childcare.

\footnotetext{
${ }^{8}$ Separate questions are asked for the respondent's children living in the household, respondent's children not living in the household, other children living in the household, and other children not living in the household. For all but the last, the children's names are filled in from the household roster. The ATUS questionnaire is available on the BLS website at http://www.bls.gov/tus/tuquestionnaire0310.pdf.

${ }^{9}$ See Schwartz (2002).

${ }^{10}$ Note that ATUS does not collect information on times when children under 13 were napping.

${ }^{11}$ Own children include biological sons or daughters, adopted children, and stepchildren.
} 
For much of our analysis, the unit of observation is the episode. The main variables of interest are the ones indicating whether the respondent had a child under 13 in their care during the episode and whether a child under 13 was present. Because we need information on both of these variables, we excluded from the sample episodes for which the respondent was not asked the who-with question. These are episodes during which the primary activity is: sleeping, grooming, personal/private activities, working at a job, could not remember, or refused. ${ }^{12}$ We also excluded episodes when the respondent was engaged in childcare as a primary activity because these episodes are already counted as childcare. Finally, we follow the BLS convention of excluding times when the respondent reported that all household children under 13 were asleep. ${ }^{13}$ Time spent with children under 13 and time spent doing secondary childcare are measured as the sum of the durations of episodes in which the respondent indicated that he or she did those activities.

\section{Basic Tabulations}

Table 1 illustrates the daily average amount of time spent in the three types of childcare. For this table, we use definitions of time with children and secondary childcare that conform with those used in BLS's published tables. ${ }^{14}$ The estimates in Table 1 were generated using ATUS sample weights.

Overall, parents spend considerably more time doing childcare as a secondary activity (with children in their care) than they spend doing childcare as a primary activity—5.8 hours per

\footnotetext{
${ }^{12}$ Starting in 2010, the who-with question was asked for episodes during which the main activity was working at a job.

${ }^{13}$ If the child went to sleep in the middle of an episode, then the episode is included in the sample and the duration is set to the portion of the episode when the child was awake.

${ }^{14}$ Secondary childcare includes any time when the respondent indicated that a child under 13 was in their care unless the primary activity was childcare, the respondent was asleep, or all household children under 13 were asleep. Thus, the main difference is that episodes for which the who-with information was not collected are included. Time with children measures the total amount of time that the respondent reports being with a child under 13 (including time spent in primary childcare).
} 
day compared with only 1.8 hours of primary childcare, with the absolute difference being larger for women than for men. Turning to the last three columns of Table 1 we can see that, on an average day, 93 percent of fathers and 98 percent of mothers spend at least some time in secondary childcare, and a similar percentage spend at least some time with children. In contrast, only 62 percent of fathers and 86 percent of mothers engage in any childcare as a primary activity on an average day. Thus, secondary childcare represents the majority of the time parents spend providing childcare, and it is something that is done almost every day.

It is also worth noting that the combined time spent in primary and secondary childcare exceeds the total amount of time spent with children. We point this out because it could be due to overreporting of secondary childcare. However, respondents could also be reporting correctly, since the secondary childcare concept permits parents to have a child "in their care" even when the child is not "with" the respondent or during activities for which the who-with information is not collected. Also, although the effect is probably small, primary childcare estimates can include time spent on care of children over the age of 13; although all individuals in our sample had at least one child under age 13, some also had older children. ${ }^{15}$

Table 2 shows the correspondence between time spent providing secondary childcare and time spent with children under 13 at the episode level. The top panel shows the fraction of inscope episodes in each of the four cells (given by with/not with children and secondary childcare/no secondary childcare), while the bottom panel shows the fraction of time spent in inscope activities in each cell. Note that average times are person-weighted averages rather episode-weighted averages. ${ }^{16}$ The last column in the top panel of Table 2 shows the number of episodes where the respondent is providing secondary childcare and is "with" a child under 13 as

\footnotetext{
${ }^{15}$ The effect is likely to be small because time with older children is more likely to be reported as the activity (for example, riding bikes) and less likely to be reported as childcare.

${ }^{16}$ Episode-weighted averages would give average episode length.
} 
a percentage of the total number of secondary childcare episodes, and the last column of the bottom panel shows the corresponding percentage of time.

The key finding in Table 2 is that about three-quarters of secondary childcare episodes are done when the child is present, which means that no child under 13 is present in one-quarter of these episodes. This percentage does not vary by sex, and we get similar results when we look at the percentage of time spent providing secondary childcare (see the lower panel of Table 2).

We might expect these percentages to depend on where the respondent was and what he or she was doing. Table 3 shows how episodes are distributed into the four cells for selected primary activities and locations. For example, respondents had a child under 13 in their care in nearly 80 percent $(38.3+39.4$ percent) of episodes when the primary activity was household work, and in about half of these episodes respondents were not with a child under 13. Leisure is the other activity for which the respondents frequently provide secondary childcare with no child present. This pattern is comforting, because we would expect providing secondary childcare with no child present to be more common for household work and leisure activities because most leisure and virtually all household work are done at home and do not necessarily entail interaction with children. Looking only at the episodes when the respondent was providing secondary childcare and no child was present, over half of the episodes are household work and more than one-quarter are leisure. ${ }^{17}$ For two activities—shopping and traveling — the respondent was either with a child and providing secondary childcare or not with a child and not providing secondary childcare in nearly all episodes. Traveling and shopping are done away from the home, so we would expect being with a child to coincide with providing secondary childcare. Likewise, we would expect being with a child to coincide with secondary childcare when eating away from home.

\footnotetext{
17 These tabulations are not shown in Table 3, but are available from the authors on request.
} 
The lower panel of Table 3 confirms that providing secondary childcare while no child is present is most likely at the respondent's home (about 30 percent of all at-home episodes compared with less than 10 percent of away-from-home episodes). The percentage is smaller, though still relatively large, when the respondent was at somebody else's home. Again looking only at the episodes when the respondent was providing secondary childcare and no child was present, nearly 90 percent of these episodes were at the respondent's home. ${ }^{18}$ Thus, the relationship between primary activities and locations of episodes, and whether a child is present during episodes of secondary childcare is consistent with our expectations.

The entries in Table 3 also suggest some possible errors in reporting. Some respondents report secondary childcare with no child present during travel and shopping (by activity) and during episodes away from home (by location). For these episodes, we would expect a child to be present, although it is possible that there is misreporting of the who-with information. These percentages are generally small, suggesting that this type of misreporting is not serious. The large fraction for Other Person's Home suggests that respondents may be answering the whowith question like they do at home (in the same room).

Overall, the high degree of internal consistency between secondary childcare and the presence of children under 13 suggests that respondents are generally reporting correctly, and that reporting errors appear to be relatively rare. However, there are reporting patterns that potentially are a cause for concern. We frequently see respondents report that a child under 13 was in their care "all day.” We also see secondary childcare reported in blocks of 8 hours or more. This could lead to overreporting if respondents are not specifically identifying times when children were not in their care.

\footnotetext{
${ }^{18}$ These tabulations are not shown in Table 3, but are available from the authors on request.
} 
Table 4 shows the fraction of respondents who report doing secondary childcare "all day" and the fraction who report at least one block of 8 hours or more. ${ }^{19}$ Note that the blocks of 8 or more hours could include times when the respondent was asleep. Overall, about 23 percent of parents reported doing secondary childcare "all day" on their diary day, and another 26 percent reported having a child under 13 in their care for at least one block of 8 hours or more. ${ }^{20}$ These fractions seem high (at least to us). The next four panels show how this fraction is affected by variables that we would expect to affect the actual amount of time spent looking after children.

The fraction reporting all day is smaller on weekdays than on weekends. The difference between weekdays and weekends is larger for men, which reflects their higher employment rates. The percentage reporting all day is very small on probable school days and workdays (note that ATUS does not identify school days—see the Appendix for variable definitions). Reports of allday secondary childcare on probable school days could be due to reporting error but could also be correct in cases when children stay home from school because they are sick or because the day was not actually a school day. As we might expect, the fraction reporting all day decreases with the age of the youngest child, and the pattern is more pronounced for women than for men.

The bottom rows of Table 4 show the relationship between all-day reporting and a proxy for interview quality—-the number of episodes reported during the interview. Respondents that take the time to report more activities should be less likely to report "all day" or a block of 8 or more hours. We find that the fraction of all-day reports declines sharply as the number of episodes increases for both mothers (from 57 to 25 percent) and fathers (from 21 to 3 percent).

\footnotetext{
${ }^{19}$ Respondents reporting doing secondary childcare "all day” and respondents reporting secondary childcare blocks of 8 hours or more are mutually exclusive groups.

${ }^{20}$ If one looks at unweighted data, the percentages are even higher. About 28 percent report all day and another 27 percent report at least one block of $8+$ hours. The main reason for the discrepancy is that the unweighted tabulations do not account for the fact that the ATUS oversamples weekends and parents spend more time with their children on weekend days than on weekdays.
} 
The relatively small decline for mothers and fathers combined is due to the combined effect of higher all-day reporting rates for women and the tendency of women to report more episodes than men. In contrast, there is surprisingly little variation in the percentage reporting at least one 8-hour block of secondary childcare time. Women are more likely to report at least one 8-hour block, but there is no recognizable pattern by day of week, school day status, workday status, or age of youngest child. Turning to the bottom panel of Table 4, the fraction reporting at least one 8-hour block of secondary childcare actually increases with the number of episodes reported.

\section{Multivariate Analysis}

The univariate tabulations in Table 4 suggest that day-specific, respondent-specific, and interview-related factors affect the likelihood that the respondent reports doing secondary childcare "all day," but that only the interview-related factors matter for block reporting. Below, we perform a multivariate analysis of these reporting patterns, which permits us to examine the effect of many more variables and to account for possible correlations between the variables. Specifically, we estimate a linear probability model to determine the effect of the different variables on the likelihood of an all-day or block report. We estimated a linear probability model instead of a probit, because the coefficients are easier to interpret and we can perform an analysis of variance (ANOVA) using the same set of results. ${ }^{21}$ The ANOVA allows us to estimate the relative importance of each factor. We did not use sample weights in this estimation, but because residuals are inherently heteroskedastic in the linear probability model, we weighted each observation, both in the linear probability model and the ANOVA, by $\sqrt{\left(\hat{P}_{i}\left(1-\hat{P}_{i}\right)\right)^{-1}}$, where the $\hat{P}_{i}$ are predicted probabilities obtained from a similarly-defined probit regression.

\footnotetext{
${ }^{21}$ Probit estimates of the marginal effects were very similar to those from the linear probability model.
} 
Each equation includes four sets of variables. Going from variables that are likely to have the greatest effect on the actual amount of time spent in secondary childcare to those that have no effect, the variables are: child-related variables, day-specific variables, demographic variables, and interview-related variables (see the Appendix for variable definitions).

The first set of variables is child-related: dummy variables for the age of the youngest child in the household, and the number of children in each of three age groups. We expect an "all day" response to be more likely the younger the youngest child and the more children under 13 there are in the household.

The second set is day-specific. As we saw above, there are large and predictable differences depending on whether the diary day is a weekend, a school day, or a workday. We also included variables for the time the respondent spent in various activities, time spent at home, and time spent with household children under 13. For example, we would expect the likelihood of providing secondary childcare all day to increase with the amount of time spent with the child. In the limit, if the respondent spent all day with the child, it would not be surprising if the child was in the respondent's care all day as well. Time spent at home and doing household work should increase the likelihood of providing secondary childcare all day. Time spent doing primary childcare should also increase the likelihood. ${ }^{22}$

The third set of variables capture the demographic characteristics of the respondent (age, race, sex, marital status, employment status, etc.). These variables could capture differences in behavior or differences in reporting. For example, we might expect non-employed parents to spend more time in childcare, increasing the likelihood that they were looking after their children

\footnotetext{
${ }^{22}$ It should be noted that, because secondary childcare is done while doing something else, the amount of time spent doing secondary childcare does not place any constraints on the time that is available for other activities or the time spent with children under 13. An increase in the amount of time spent doing secondary childcare does not imply a reduction in the time spent doing something else because there is no adding-up constraint.
} 
all day. They may also feel that it is important to look like a good parent and report doing secondary childcare “all day” whether or not they actually did so.

The final set of variables is interview-related and includes dummy variables for interviewer effects and two proxies for interview quality: the amount of time spent in uncodeable activities, and the total number of episodes reported for the diary day. Interviewer effects capture differences in interviewers’ abilities to elicit more-detailed information from respondents. The last two variables are intended to capture the respondent's propensity to provide detailed answers. We expect respondents to be less willing to take the time to identify specific episodes of secondary childcare the fewer episodes they report on their diary day (indicating that they are combining activities) and the greater the amount of time spent in activities that could not be coded (indicating that their responses were not very detailed). If these variables matter after having controlling for other factors, then we have reason to suspect the quality of secondary childcare reports.

The coefficient estimates in Table 5a show the effect of these variables on the probability that the respondent reports doing secondary childcare "all day” and the probability of reporting at least one block of 8 or more hours (including “all day”). The child-related variables have very little effect. Only three variables are statistically significant $(\mathrm{p}<.05)$ in the all-day equation and all of these coefficients are small. Only one child-related variable is statistically significant in the block equation, and it's coefficient is small as well.

The day-specific variables are generally positive-signed and most are statistically significant. Time spent with children and its square have by far the largest effect on the probability of an "all day” report. The signs on the time and time-squared terms implies that the effect of time with children is convex, so that the effect becomes very large when parents spend a 
lot of time with their children on the diary day. Spending 4 hours with a child under 13 increases the probability of an all-day report by 5 percentage points, spending 8 hours increases the probability by 25 percentage points, and spending 12 hours increases the probability by 62 percentage points. The effect of these variables on block reporting is large, but it does not increase as rapidly for high values of time with children. Time spent in primary childcare has a relatively small effect. Spending two hours doing primary childcare time increases the probabilities by 3 and 6 percentage points, respectively. An "all day” response is about 5 percentage points less likely on a workday. Time spent working during the diary day is negative-signed. But combined with the coefficient on the dummy for working on the diary day, working reduces the probability of an all-day response, and the effect is less negative when the respondent worked at home.

The demographic variables have very small marginal effects. Only the dummy variable for employment status has an effect that is statistically significant and large enough to be meaningful. The generally small coefficients on the demographic variables suggest that any social-desirability bias related to demographic characteristics is likely to be small.

Of key interest is the effect of the interview-related variables. The interviewer dummies (not shown in Table 5a) and the time spent in uncodeable activities had virtually no effect. The number-of-episodes variable had a small effect. For every 5 episodes reported the probability of an all-day report decreased by 1 percentage point.

The coefficient estimates tell us how strongly the probability of an "all day" response is related to the probability of reporting secondary childcare, but they do not tell us how much of the variation in secondary childcare is due to each of these factors. To answer this question, we performed a sequential analysis of variance (ANOVA). In this type of analysis, the order of the 
variables matters. A given variable will explain more of the variation if it is entered first (before the effects of the other variables have been controlled for) than if it is entered last. Our strategy is to include child-related variables first, day-related variables second, demographic variables third, and interview-related variables last. To place an upper bound on the effect of the interview-related variables we performed a reverse-order sequential ANOVA, with the interview-related variables being entered first and the child-related variables being entered last.

The first set of ANOVA results are presented in Table 5b under the "Order Listed" column. Each entry is the percent of total variation explained by that group of variables. We can see that the day-related variables account for 39 percent of total variance, which translates to 89 percent of explained variance. Nearly all of this is due to the time-with-children variables. The interview-related variables accounted for about 3 percent of total variation or less than 10 percent of explained variation. The reverse-order ANOVA, shown in the second column of Table 5b, does not contradict these results. The percent of variation explained by interview-related variables increased to 8 percent of total variation or about one-fifth of explained variation, while the share explained by day-related variables fell to just under 30 percent. But the story that time spent with children is the primary determinant of whether the respondent reports "all day" to the secondary childcare question remains intact.

The last two columns of Table 5b show the ANOVA results when the dependent variable is defined to include 8+ hour blocks as well as “all day" reporting. In this equation, we have explained a much larger portion of the total variation. The results in the third column are consistent with those in the first two columns. The day-related variables account for half of all variation and 84 percent of explained variation. Interview-related variables account for less than 5 percent of total variation. But in the reverse-order ANOVA, the fraction of total variation 
explained by day-related variables drops to 23 percent of total variation (37 percent of explained variation), while the variation explained by interview-related variables increases to 31 percent or about one-half of explained variation. In both columns the effect of the interview-related variables is entirely due to interviewer effects. Thus it appears that interviewer effects are more important for block reporting than "all day” reporting.

\section{Episode-Level Analysis}

Another way to assess the quality of the secondary childcare measure in ATUS is to perform an episode-level analysis of the responses. Tables $6 \mathrm{a}$ and $6 \mathrm{~b}$ examine the likelihood that a child under 13 was present during an episode of secondary childcare. The universe for Table 6a is episodes for which who-with information was collected during and during which the respondent reported doing secondary childcare. The dependent variable equals one if the respondent was "with" a child under 13, so the coefficients indicate the effect of the variables on the probability that a child under 13 was present, given that the respondent reported doing secondary childcare.

As in the "all day" regression, we have included four sets of variables. The child-related and demographic variables are the same as in Table 5a. The interview-related variables are the same except for the addition of dummy variables for whether the respondent reported providing secondary childcare "all day” and whether the episode is in an 8-or-more-hour block of secondary childcare. If respondents are not reporting carefully, we might expect it to be less likely that the respondent was with a child under 13 if the episode was in an 8-or-more-hour block or if the respondent reported doing secondary childcare all day. Our expectations for the remaining variables are the same as they were for the regressions in Table 5a. Instead of the day-related variables, we have entered the following episode-specific variables: the duration of 
the episode, the starting time of the episode (morning or afternoon), whether the respondent's spouse was present (if married), whether the respondent was at home, and dummy variables for different activities (household work, eating, watching TV, watching sports, participating in sports, and travel). Because of the way that the who-with variable is defined, we expect that respondents will be less likely to be with a household child under 13 if they are providing secondary childcare at home. We would also expect the respondent to be less likely to be with a child if the primary activity was household work and more likely to be with a child under 13 if the primary activity was eating.

The coefficient estimates in Table 6a are in line with our expectations. Unlike the regression in Table 5a, the coefficients on the age-of-youngest-child variables have the expected signs, are fairly large, and are statistically significant. The number-of-children variables are statistically significant, but the effects are small.

The episode-related variables have large and statistically significant effects. As expected, respondents are less likely to be "with" a child under 13 if they are at home when providing secondary childcare or if their main activity was household work. They are more likely to be "with" a child when providing secondary childcare during mealtimes and when traveling. The effect when traveling by car is smaller, though still positive $(0.0699=0.1098-0.0399)$. Married respondents are more likely to be "with" a child under 13 if their spouses are also present.

The demographic variables have a very small effect. Single parents are less likely to be with a child under 13 when providing secondary care and women are slightly more likely.

The coefficients on the interview-related variables are generally small, even when they are statistically significant. For example, every 10 episodes reported increases the probability by only one-half of one percentage point. Respondents who reported providing secondary childcare 
"all day” were slightly more likely to be with a child under 13 when providing secondary childcare. This reflects the fact that "all day" reporters spend more than twice as much time with their children under $13-8$ hours per day vs. 3.6 hours for those who did not say "all day." The absence of a large effect suggests that "all day" reporting is not problematic, and that these respondents are not exaggerating the time spent in secondary childcare.

The ANOVA results in Table 6b indicate that the episode-related variables account for 24 percent of the total variation, and nearly all of the variation explained by the model. The interview-related variables have virtually no effect. Even in the reverse-order ANOVA, the effect of the interview-related variables is small—less than 5 percent of total variation and 12 percent of explained variation.

To summarize the results in Tables 5a, 5b, 6a, and $6 \mathrm{~b}$, the main determinant of whether the respondent reports doing secondary childcare as a block of 8 or more hours or "all day" is the amount of time spent with a household child under 13. "All day” and block reporters are more likely to have a household child under 13 present when providing secondary childcare, which suggests that overreporting of secondary childcare is not a problem for these types of reports. The interview-related variables explain very little of the variation in the fraction of respondents who report doing secondary childcare in 8-hour blocks or "all day" or the variation in the likelihood that the respondent is with a child under 13 when providing secondary childcare. ${ }^{23}$

\footnotetext{
${ }^{23}$ Related to this episode-level analysis is the fraction of secondary childcare time spent in the presence of a child under 13. In results not shown here, we examined the determinants of this fraction in a regression framework. We included the same independent variables as in Table 5a, except that we dropped the total amount of time spent with a child under 13 and added indicators for whether the respondent reported doing secondary childcare for an 8+ hour block of time or "all day." Most of the coefficients were small and not statistically significant. However, parents who reported doing secondary childcare "all day" had a child under 13 present for a larger fraction of secondary childcare time than other respondents. This is consistent with our earlier finding that these parents spend considerably more time with their children than other respondents. Finally, these covariates explain very little of total variation in the fraction of secondary childcare time spent in the presence of a child under 13.
} 


\section{Alternative Estimates}

Our final question is: "How much do these possible sources of overreporting affect the estimates of secondary childcare?” To answer this question, we constructed several alternative estimates that exclude episodes for which misreporting is most likely. .

The official ATUS estimates of secondary childcare time are tabulations of the "in your care” responses and do not contain many edits other than omitting time when either the respondent or all household children were asleep. ${ }^{24}$ Time when the respondent was engaged in primary childcare is also omitted to avoid double counting.

The three alternative estimates exclude "in your care" time that may have been reported in error - time that occurred when: (1) the child was likely to be in school, (2) the respondent did not report being "with" a child under age 13 at any point during the diary day, and (3) the respondent was not at home or another's home and was not “with” a child under age 13 during the episode. Lastly, all three estimates were combined to evaluate the total impact on time spent in secondary childcare.

For the first adjustment, we excluded all secondary childcare that occurred on probable school days between 8:30am and 3:00pm unless the respondent reported being "with" a child under age 13 at some time during the interval between 9:30am and 2:00pm. This allows for the possibility that the child was not in school due to sickness or vacation or because the day was not actually a school day. We imposed this adjustment only on respondents whose youngest child was age 6 or older as younger children would be far less likely to be attending school.

\footnotetext{
${ }^{24}$ A few edits are done on very improbable wake and sleep times of household children. Missing, don't know, and refused child wake and sleep times are set to 4 a.m., and wake times of 1 a.m., 2 a.m., 3 a.m., or greater than 4 p.m. are set to 4 a.m. Official ATUS estimates also contain some records that are imputed, but these observations are deleted from our sample.
} 
The school time exclusion did not have a large impact on the estimates of time spent in secondary childcare (see Table 7). It lowered the estimate of time spent by both parents from 5.75 hours to 5.71 hours-a difference of approximately two minutes. The difference for fathers was only about 1 minute, and the difference for mothers was about 3 minutes. These results are consistent with our earlier findings that "all day" reporting on probable school days is rare, and suggest that few people report having a child "in their care" when the child is actually at school. If large numbers of people were consistently answering the "in your care" question in this fashion, we would expect the difference in these estimates to be greater.

The second alternative estimate excluded “in your care” time when the respondent didn’t report being "with” a household child under 13 at any point during the diary day. These types of reports could be errors in reporting times when children were present. Or it could be that parents who did not spend time with their children are reporting "in your care" time because they "feel responsible” for their children.

This exclusion had a larger impact on secondary childcare estimates than did the omission of probable school time, but the effect is still fairly small. The estimated time spent in secondary childcare drops from 5.75 hours to 5.67 hours, a difference of about 5 minutes. In this alternative estimate, fathers spent about 8 minutes less in secondary childcare compared to about 2 minutes less for mothers.

In the third alternative estimate, we exclude "in your care” time that occurred when the respondent was not with a child under 13 and was neither at home nor at another person's home. $^{25}$ If the respondent is not in one of these two locations, we can reasonably expect parents

\footnotetext{
${ }^{25}$ We did not try to exclude situations in which the where and who with information was not collected. For example, if a person reported grooming with a child "in their care," we would have no where or who with information to work with. It is possible to impute much of the where information by using where information in adjacent activities. For
} 
to be with their child when providing secondary childcare. While such situations may be legitimate—a parent may be getting takeout while a child is in a restaurant's play area—some are almost certainly errors. For example, it is an error if a respondent reports driving a car with a child "in their care” but does not report being accompanied by a child.

This exclusion has a larger impact on the estimates of secondary childcare than do the other two exclusions. The estimate for both parents drops from 5.75 hours to 5.58 hours, a difference of about 10 minutes. The difference is slightly greater for mothers than for fathers11 minutes versus 9 minutes.

The final alternative estimate in Table 7 shows the combined effect of the three exclusions on the secondary childcare estimates. The total effect is to lower estimated secondary childcare time by about 16 minutes per day. Fathers show a slightly larger difference than mothers—17 minutes as opposed to 15 .

These alternative estimates, along with the multivariate analyses presented earlier, indicate that while there is likely some overreporting of the "in your care" question in the ATUS, the effects are relatively small.

\section{Summary and Conclusion}

Secondary childcare time accounts for most of the time spent in childcare as measured in the ATUS. Because secondary childcare care estimates are so much larger than the estimates from earlier U.S. time-use surveys, there has been a concern that the ATUS estimates are too large. Such an overstatement would be problematic for researchers studying factors affecting parents' childcare choices, and could lead to overestimates of the aggregate amount of time spent 
caring for children. The latter issue has potentially important implications for the creation of nonmarket satellite accounts to the NIPAs.

Our episode-level analysis shows that no child is present during about one-quarter of all episodes when respondents reported having a child under 13 in their care. Further investigation shows that the vast majority of these episodes occurred at home, which is consistent with the ATUS definition of secondary childcare. We investigated respondents’ reporting patterns, and found that a large fraction of respondents reported that a child under 13 was in their care "all day” or for a block of 8 hours or more. However, these respondents also spent considerably more time with their children. Our multivariate analysis showed that time spent with children explained 39 percent of the total variation in all-day reports (about 89 percent of explained variation) and 52 percent of the variation in all-day/block reporting (about 84 percent of explained variation). Further, respondents who gave an “all day” report were more likely to report that a child was present during episodes of secondary childcare, but the effect of this variable on total variation is relatively small. Most of the explained variation in whether a child was present during a secondary childcare episode is due to episode-specific variables.

We also found that interview-related variables explained very little of the variation in the likelihood of an all-day/block report and the likelihood that a child under 13 was with the respondent during an episode of secondary childcare. However, this may be due the paucity of interview-related variables. It is possible that the effects would be stronger if we had more and better indicators of interview quality. Demographic variables also had very little effect, which implies that any differences across demographic groups are due to real differences in things such as the amount of time spent with children, rather than any differences in reporting. 
Finally, our alternative estimates of secondary childcare, which exclude episodes that were inconsistent with other information in the diary, indicate that secondary childcare is overreported by at most 5 percent or about 16 minutes per day. Thus, we conclude that the secondary childcare questions in the ATUS are collecting the information they were designed to collect, and that secondary childcare is overestimated by at most a small amount. 


\section{Appendix - Variable Definitions}

Outcome variables

All day: An all-day response occurs when the respondent indicates that a child under 13 was “in your care” during all episodes.

8+ hour block: The respondent reported doing secondary childcare in contiguous episodes that spanned at least 8 hours. Note that this could include time spent sleeping.

\section{Day-specific variables}

School day: The diary day is a non-holiday weekday between September $15^{\text {th }}$ and

December $15^{\text {th }}$ or between January $15^{\text {th }}$ and May $15^{\text {th }}$. A diary day can be considered a probable school day only if the youngest child in the household is 6 or older

Workday: A day on which the respondent spent any time working (either at home or at the workplace).

Summer: The diary day was between June 1 and August 31, inclusive.

\section{Episode-specific variables}

Morning: Episode started at or after 4:00AM but before 12:00 noon.

Afternoon: Episode started at or after 12:00 noon but before 8:00PM. 


\section{References}

Allard, Mary Dorinda, Suzanne Bianchi, Jay Stewart, and Vanessa Wight "Comparing Childcare Measures in the ATUS and Earlier Time-Diary Studies” Monthly Labor Review 130(5), May 2007, pp. 27-36.

Folbre, Nancy, Jayoung Yoon, Kade Finnoff, and Allison Sidle Fuligni. (2005) "By What Measure? Family Time Devoted to Children in the United States.” Demography. 42 (May): 373-390.

Kahneman, Daniel, Alan Krueger, David Schkade, Norbert Schwarz, and Arthur Stone (2004) "A Survey Method for Characterizing Daily Life Experience: The Day Reconstruction Method” Science 306, December 3, 2004, pp. 1776-1780.

Landefeld, J. Steven, Barbara M. Fraumeni, and Cindy M. Vojtech. (2009) “Accounting for Nonmarket Production: A Prototype Satellite Account Using the American Time Use Survey.” Review of Income and Wealth. 55(2).

Schwartz, Lisa K. (2002) “The American Time Use Survey: Cognitive Pretesting.” Monthly Labor Review. 125 (February): 34-44. 
Table 1: Time Spent With and Caring for Own Household Children Under 13

\begin{tabular}{|c|c|c|c|c|c|c|}
\hline & \multicolumn{3}{|c|}{ Time Spent. } & \multicolumn{3}{|c|}{ Percent Reporting... } \\
\hline & $\begin{array}{l}\text { In Childcare as } \\
\text { Primary Activity }\end{array}$ & $\begin{array}{c}\text { In Childcare as } \\
\text { Secondary } \\
\text { Activity }\end{array}$ & $\begin{array}{c}\text { With Children } \\
\text { Under } 13\end{array}$ & $\begin{array}{c}\text { Doing Any } \\
\text { Childcare as a } \\
\text { Primary Activity }\end{array}$ & $\begin{array}{l}\text { Doing Any } \\
\text { Secondary } \\
\text { Childcare }\end{array}$ & $\begin{array}{c}\text { Spending Any } \\
\text { Time with } \\
\text { Children Under } \\
13 \\
\end{array}$ \\
\hline All & 1.82 & 5.78 & 5.59 & 74.6 & 95.9 & 96.7 \\
\hline Fathers & 1.15 & 4.60 & 4.32 & 61.7 & 93.3 & 94.8 \\
\hline Mothers & 2.39 & 6.79 & 6.68 & 85.7 & 98.1 & 98.4 \\
\hline
\end{tabular}

Notes: The universe for this table is parents with at least one own child under 13 living in the household, no non-own household children, and no other adult household members except a spouse. Primary childcare also includes time spent caring for children 13 and over. Time spent with children and time doing secondary childcare exclude times when the respondent reported doing childcare as a primary activity. Time spent with children also excludes episodes for which who-with information was not collected. These estimates are weighted using ATUS sample weights. 
Table 2: Time Spent in Secondary Childcare vs. Time With Children under 13

\begin{tabular}{|c|c|c|c|c|c|c|}
\hline & \multicolumn{4}{|c|}{ Percent of Episodes } & \multirow[b]{3}{*}{ Total } & \multirow{3}{*}{$\begin{array}{c}\text { Percent of Secondary } \\
\text { Childcare Episodes Done } \\
\text { With a Child Under } 13 \\
\text { Present as a Percent of } \\
\text { All Secondary Childcare } \\
\text { Episodes }\end{array}$} \\
\hline & \multicolumn{2}{|c|}{$\begin{array}{c}\text { Not Providing Secondary } \\
\text { Childcare }\end{array}$} & \multicolumn{2}{|c|}{ Providing Secondary Childcare } & & \\
\hline & $\begin{array}{c}\text { Not With a } \\
\text { Child under } 13 \\
\end{array}$ & $\begin{array}{c}\text { With a Child } \\
\text { Under } 13 \\
\end{array}$ & $\begin{array}{c}\text { Not With a } \\
\text { Child under } 13 \\
\end{array}$ & $\begin{array}{c}\text { With a Child } \\
\text { Under } 13 \\
\end{array}$ & & \\
\hline All & 37.9 & 2.3 & 16.1 & 43.8 & 100 & 73.14 \\
\hline Fathers & 48.5 & 3.7 & 12.7 & 35.2 & 100 & 73.57 \\
\hline \multirow[t]{4}{*}{ Mothers } & 31.0 & 1.3 & 18.3 & 49.4 & 100 & 72.94 \\
\hline & \multicolumn{4}{|c|}{ Percent of Available Time } & & \multirow{3}{*}{$\begin{array}{l}\text { Percent of Time Spent in } \\
\text { Secondary Childcare Done } \\
\text { With a Child Under } 13 \\
\text { Present as a Percent of } \\
\text { All Time Spent in } \\
\text { Secondary Childcare } \\
\end{array}$} \\
\hline & \multicolumn{2}{|c|}{$\begin{array}{c}\text { Not Providing Secondary } \\
\text { Childcare }\end{array}$} & \multicolumn{2}{|c|}{ Providing Secondary Childcare } & & \\
\hline & $\begin{array}{c}\text { Not With a } \\
\text { Child under } 13 \\
\end{array}$ & $\begin{array}{l}\text { With a Child } \\
\text { Under } 13\end{array}$ & $\begin{array}{c}\text { Not With a } \\
\text { Child under } 13 \\
\end{array}$ & $\begin{array}{c}\text { With a Child } \\
\text { Under } 13 \\
\end{array}$ & Total & \\
\hline All & 32.2 & 2.5 & 17.9 & 47.4 & 100 & 72.63 \\
\hline Fathers & 39.8 & 4.0 & 15.6 & 40.6 & 100 & 72.20 \\
\hline Mothers & 26.5 & 1.5 & 19.5 & 52.5 & 100 & 72.88 \\
\hline
\end{tabular}

Notes: The universe for this table is parents with at least one own child under 13 living in the household, no non-own household children, and no other adult household members except a spouse. Estimates in the top panel are unweighted. Estimates in the bottom panel are weighted using ATUS sample weights. Available time is time that is in-scope for secondary childcare (times when both parent and child are awake, excluding activities for which the who-with information is not collected). 
Table 3: Time Spent in Secondary Childcare vs. Time With Children under 13 by Activity

\begin{tabular}{|c|c|c|c|c|c|c|}
\hline \multirow[b]{3}{*}{ Selected Activities } & \multicolumn{5}{|c|}{ Percent of In-Scope Episodes } & \multirow{3}{*}{$\begin{array}{c}\text { Percent of Secondary } \\
\text { Childcare Episodes Done } \\
\text { With a Child Under } 13 \\
\text { Present as a Percent of } \\
\text { All Secondary Childcare } \\
\text { Episodes }\end{array}$} \\
\hline & \multicolumn{2}{|c|}{$\begin{array}{c}\text { Not Providing Secondary } \\
\text { Childcare }\end{array}$} & \multicolumn{2}{|c|}{ Providing Secondary Childcare } & \multirow[b]{2}{*}{ All Episodes } & \\
\hline & $\begin{array}{c}\text { Not With a } \\
\text { Child under } 13 \\
\end{array}$ & $\begin{array}{l}\text { With a Child } \\
\text { Under } 13 \\
\end{array}$ & $\begin{array}{c}\text { Not With a } \\
\text { Child under } 13\end{array}$ & $\begin{array}{l}\text { With a Child } \\
\text { Under } 13 \\
\end{array}$ & & \\
\hline Household Work & 20.9 & 1.4 & 38.3 & 39.4 & 100.0 & 50.71 \\
\hline Shopping & 47.9 & 1.7 & 3.5 & 47.0 & 100.0 & 93.07 \\
\hline Eating and Drinking & 31.2 & 4.3 & 6.7 & 57.9 & 100.0 & 89.58 \\
\hline Leisure & 25.7 & 3.0 & 23.6 & 47.7 & 100.0 & 66.89 \\
\hline Sports Exercise \& Recreation & 47.2 & 1.4 & 12.8 & 38.6 & 100.0 & 75.16 \\
\hline \multirow[t]{3}{*}{ Traveling } & 57.0 & 1.6 & 2.1 & 39.4 & 100.0 & 94.96 \\
\hline & \multicolumn{5}{|c|}{ Percent of In-Scope Episodes } & Percent of Secondary \\
\hline & \multicolumn{2}{|c|}{$\begin{array}{c}\text { Not Providing Secondary } \\
\text { Childcare }\end{array}$} & \multicolumn{2}{|c|}{ Providing Secondary Childcare } & & $\begin{array}{l}\text { Childcare Episodes Done } \\
\text { With a Child Under } 13\end{array}$ \\
\hline Selected Locations & $\begin{array}{c}\text { Not With a } \\
\text { Child under } 13 \\
\end{array}$ & $\begin{array}{c}\text { With a Child } \\
\text { Under } 13 \\
\end{array}$ & $\begin{array}{c}\text { Not With a } \\
\text { Child under } 13\end{array}$ & $\begin{array}{l}\text { With a Child } \\
\text { Under } 13 \\
\end{array}$ & All Episodes & $\begin{array}{l}\text { All Secondary Childcare } \\
\text { Episodes }\end{array}$ \\
\hline Respondent's Home & 18.0 & 2.9 & 30.3 & 48.9 & 100.0 & 61.75 \\
\hline Respondent's Work & 97.3 & 0.3 & 0.8 & 1.5 & 100.0 & 64.83 \\
\hline Other Person's Home & 32.7 & 2.9 & 9.9 & 54.5 & 100.0 & 84.60 \\
\hline Restaurant/Bar & 46.7 & 1.7 & 1.7 & 50.0 & 100.0 & 96.75 \\
\hline Store & 48.3 & 1.8 & 3.2 & 46.8 & 100.0 & 93.60 \\
\hline Car (driver) & 59.7 & 1.6 & 2.0 & 36.6 & 100.0 & 94.73 \\
\hline Car (passenger) & 34.8 & 1.7 & 1.2 & 62.4 & 100.0 & 98.13 \\
\hline Total & 37.9 & 2.3 & 16.1 & 43.8 & 100.0 & 73.14 \\
\hline Observations & 38,359 & 2,376 & 18,884 & 54,431 & 114,050 & \\
\hline
\end{tabular}

Notes: The universe for this table is parents with at least one own child under 13 living in the household, no non-own household children, and no other adult household members except a spouse. In-scope episodes refer to episodes that are in-scope for secondary childcare (episodes when both parent and child are awake, excluding episodes for which the who-with information is not collected). These tabluations do not use ATUS sample weights. 


\begin{tabular}{|c|c|c|c|c|c|c|}
\hline & \multicolumn{3}{|c|}{ All Day } & \multicolumn{3}{|c|}{ 8-Hour Block (excluding "All Day") } \\
\hline & $\begin{array}{c}\text { Mothers and } \\
\text { Fathers }\end{array}$ & Mothers & Fathers & $\begin{array}{c}\text { Mothers and } \\
\text { Fathers } \\
\end{array}$ & Mothers & Fathers \\
\hline All & 22.7 & 30.7 & 13.3 & 25.9 & 29.7 & 21.4 \\
\hline \multicolumn{7}{|l|}{ Day of Week } \\
\hline Weekday & 14.6 & 22.7 & 5.0 & 26.0 & 31.0 & 20.1 \\
\hline Weekend & 41.1 & 49.0 & 32.0 & 25.7 & 26.6 & 24.6 \\
\hline \multicolumn{7}{|l|}{ School Day Status } \\
\hline School Day & 3.8 & 5.4 & 1.7 & 26.2 & 29.7 & 21.6 \\
\hline Not a School Day & 26.3 & 35.9 & 15.4 & 25.8 & 29.7 & 21.4 \\
\hline \multicolumn{7}{|l|}{ Workday Status } \\
\hline Work Day & 4.9 & 7.3 & 3.2 & 25.2 & 32.8 & 19.8 \\
\hline Nonwork Day & 42.7 & 46.6 & 34.4 & 26.7 & 27.6 & 24.9 \\
\hline \multicolumn{7}{|c|}{ Age of Youngest Child } \\
\hline Age $<1$ & 35.8 & 51.7 & 16.2 & 23.0 & 28.0 & 16.9 \\
\hline Age $=1$ & 29.0 & 42.3 & 12.7 & 26.2 & 29.9 & 21.7 \\
\hline Age $=2$ & 26.5 & 36.7 & 16.7 & 24.2 & 27.4 & 21.1 \\
\hline Age $=3$ & 25.9 & 37.3 & 13.9 & 25.4 & 27.4 & 23.3 \\
\hline Age $=4$ & 25.4 & 32.2 & 17.1 & 26.7 & 29.7 & 23.1 \\
\hline Age $=5$ & 20.3 & 31.5 & 9.3 & 26.3 & 35.0 & 17.6 \\
\hline Age $=6-8$ & 17.1 & 20.6 & 12.8 & 28.8 & 32.6 & 24.2 \\
\hline Age $=9-12$ & 13.4 & 15.7 & 10.3 & 25.5 & 28.4 & 21.6 \\
\hline \multicolumn{7}{|l|}{ Number of Episodes } \\
\hline $5-9$ & 32.4 & 56.9 & 20.6 & 5.4 & 5.0 & 5.5 \\
\hline $10-14$ & 28.1 & 48.3 & 18.2 & 13.9 & 14.6 & 13.5 \\
\hline $15-19$ & 22.3 & 35.0 & 12.8 & 24.8 & 28.9 & 21.7 \\
\hline $20-24$ & 21.5 & 30.1 & 11.1 & 27.0 & 29.1 & 24.5 \\
\hline $25-29$ & 20.3 & 25.3 & 11.6 & 33.2 & 34.8 & 30.4 \\
\hline $30-39$ & 19.3 & 23.4 & 7.7 & 33.4 & 34.7 & 29.7 \\
\hline $40+$ & 22.8 & 25.2 & 3.3 & 33.0 & 32.9 & 33.4 \\
\hline
\end{tabular}

Note: These estimates are weighted using ATUS sample weights. 
Table 5a: Linear Probability Model of Block Reporting of Secondary Childcare

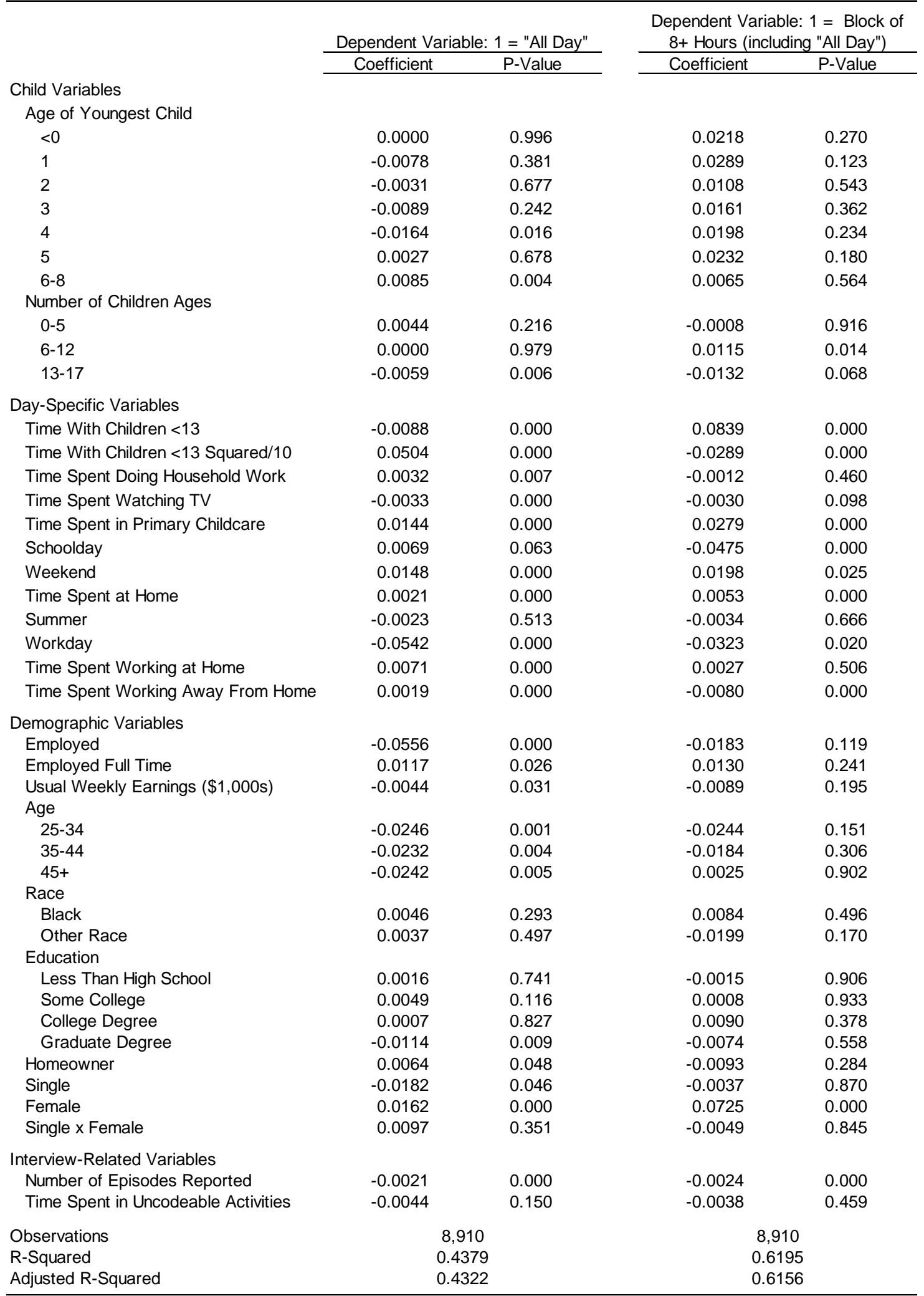

Note: The universe for this table is all respondents in the sample (see text for sample definition). Regressions include dummy variables to control for interviewer effects. ATUS sample weights were not used. See text for details on weighting. 
Table 5b: Analysis of Variance of Block Reporting of Secondary Childcare

\begin{tabular}{|c|c|c|c|c|}
\hline & \multicolumn{2}{|c|}{ Dependent Variable: 1 = "All Day" } & \multicolumn{2}{|c|}{$\begin{array}{c}\text { Dependent Variable: } 1 \text { = Block of } \\
8+\text { Hours (including "All Day") }\end{array}$} \\
\hline & \multicolumn{2}{|c|}{ Percent of Total Variance: } & \multicolumn{2}{|c|}{ Percent of Total Variance: } \\
\hline & Order Listed & Reverse Order & Order Listed & Reverse Order \\
\hline Child Variables & 1.0 & 0.2 & 4.4 & 0.1 \\
\hline Day-Specific Variables & 39.2 & 28.1 & 52.2 & 22.8 \\
\hline Demographic Variables & 0.6 & 7.1 & 0.6 & 8.3 \\
\hline Interview-Related Variables & 3.0 & 8.3 & 4.8 & 30.8 \\
\hline R-Squared & 43.8 & 43.8 & 61.9 & 61.9 \\
\hline
\end{tabular}

Note: The universe for this table is all respondents in the sample (see text for sample definition). Regressions include dummy variables to control for interviewer effects. ATUS sample weights were not used. See text for details on weighting. 
Table 6a: Linear Probability Model of Being "With" Children Under 13 During Episodes of Secondary Childcare

\begin{tabular}{|c|c|c|}
\hline & \multicolumn{2}{|c|}{ Dep. Var.: 1 = "With" Child $<13$} \\
\hline & Coefficient & P-Value \\
\hline \multicolumn{3}{|l|}{ Child Variables } \\
\hline \multicolumn{3}{|l|}{ Age of Youngest Child } \\
\hline$<0$ & 0.0415 & 0.000 \\
\hline 1 & 0.0649 & 0.000 \\
\hline 2 & 0.0468 & 0.000 \\
\hline 3 & 0.0537 & 0.000 \\
\hline 4 & 0.0470 & 0.000 \\
\hline 5 & 0.0364 & 0.000 \\
\hline $6-8$ & 0.0288 & 0.000 \\
\hline \multicolumn{3}{|l|}{ Number of Children Ages } \\
\hline $0-5$ & 0.0111 & 0.000 \\
\hline $6-12$ & 0.0057 & 0.000 \\
\hline $13-17$ & -0.0153 & 0.000 \\
\hline \multicolumn{3}{|l|}{ Episode-Specific Variables } \\
\hline Duration & 0.0031 & 0.042 \\
\hline Morning & 0.0893 & 0.000 \\
\hline Afternoon & 0.0874 & 0.000 \\
\hline Spouse Present & 0.1321 & 0.000 \\
\hline At Home & -0.1607 & 0.000 \\
\hline Activity was Household Work & -0.1505 & 0.000 \\
\hline Activity was Eating & 0.1474 & 0.000 \\
\hline Activity was Watching TV & 0.0257 & 0.000 \\
\hline Activity was Watching Sports & 0.0356 & 0.204 \\
\hline Activity was Participating in Sports & -0.0136 & 0.269 \\
\hline Activity was Traveling & 0.1098 & 0.000 \\
\hline Activity was Traveling (in car) & -0.0399 & 0.000 \\
\hline \multicolumn{3}{|l|}{ Demographic Variables } \\
\hline Employed & 0.0066 & 0.070 \\
\hline Employed Full Time & -0.0075 & 0.041 \\
\hline Usual Weekly Earnings (\$1,000s) & 0.0060 & 0.021 \\
\hline \multicolumn{3}{|l|}{ Age } \\
\hline $25-34$ & 0.0093 & 0.102 \\
\hline $35-44$ & 0.0094 & 0.128 \\
\hline $45+$ & -0.0142 & 0.049 \\
\hline \multicolumn{3}{|l|}{ Race } \\
\hline Black & -0.0115 & 0.021 \\
\hline Other Race & -0.0170 & 0.002 \\
\hline \multicolumn{3}{|l|}{ Education } \\
\hline Less Than High School & 0.0157 & 0.002 \\
\hline Some College & 0.0012 & 0.716 \\
\hline College Degree & -0.0045 & 0.205 \\
\hline Graduate Degree & -0.0041 & 0.349 \\
\hline Homeowner & 0.0039 & 0.214 \\
\hline Single & -0.1081 & 0.000 \\
\hline Female & 0.0284 & 0.005 \\
\hline Single $\times$ Female & 0.0062 & 0.558 \\
\hline \multicolumn{3}{|l|}{ Interview-Related Variables } \\
\hline Number of Episodes Reported & 0.0005 & 0.001 \\
\hline Time Spent in Uncodeable Activities & 0.0025 & 0.231 \\
\hline Episode is in Block of $8+$ Hours & -0.0034 & 0.292 \\
\hline Reported Secondary Childcare "All Day" & 0.0156 & 0.000 \\
\hline Observations & \multicolumn{2}{|c|}{73,315} \\
\hline R-Squared & \multicolumn{2}{|c|}{0.2723} \\
\hline Adjusted R-Squared & \multicolumn{2}{|c|}{0.2713} \\
\hline
\end{tabular}

Note: The universe for this table is episodes during which the respondent reported providing secondary childcare. The regression also includes dummy variables to control for interviewer effects. ATUS sample weights were not used. See text for details on weighting. 
Table 6b: Analysis of Variance of Being "With" Children Under 13 During Episodes of Secondary Childcare

\begin{tabular}{lcc}
\hline \hline & \multicolumn{2}{c}{ Dependent Variable: 1 = "All Day" } \\
\cline { 2 - 3 } & \multicolumn{2}{c}{ Percent of Total Variance: } \\
\cline { 2 - 3 } Child Variables & 1.8 & Reverse Order \\
\cline { 2 - 3 } Episode-Specific Variables & 23.6 & 0.4 \\
Demographic Variables & 1.1 & 22.4 \\
Interview-Related Variables & 0.6 & 1.1 \\
R-Squared & 27.2 & 3.2 \\
\cline { 2 - 2 }
\end{tabular}

Note: The universe for this table is all respondents in the sample (see text for sample definition). Regressions include dummy variables to control for interviewer effects. ATUS sample weights were not used. See text for details on weighting. 
Table 7: Alternative Estimates of Secondary Childcare

\section{Secondary Childcare Measures}

Current ATUS Measure

Alternative \#1 - Omits probable school time

Alternative \#2 - Omits "in your care" time if the respondent was

never with a child under 13

Alternative \#3 - Omits "in your care" time if the respondent was

not at home or another's home and was not with a child under 13

Alternative \#4 - Includes Alternatives \#1, \#2, and \#3
All

5.75

5.71

5.67

5.58

5.48
Fathers

Mothers

4.57

6.74

4.55

6.69

4.44

6.70

4.43

6.56

4.29

6.49

Notes: The universe for this table is parents with at least one own child under 13 living in the household, no non-own household children, no own non-household children, and no other adult household members except a spouse. Estimates of the current ATUS methodology are slightly different than estimates in table 1 because they use ATUS sample weights that use a slightly different methodology. 